\title{
A INFLUÊNCIA DA NARRAÇÃO NA COMPREENSÃO DA MENSAGEM: UMA ANÁLISE RETÓRICA DA PROPAGANDA “MUDANÇA” DO ITAÚ
}

\author{
Hana Luzia de Abreu Leite \\ Universidade Federal de Pernambuco \\ hanaluzia@gmail.com \\ Othon César Vasconcelos Silva \\ Universidade Federal de Pernambuco \\ othon.vasconcelos@gmail.com \\ Eva Rolim Miranda \\ Universidade Federal de Pernambuco \\ evarolim@gmail.com \\ Hans da Nóbrega Waechter \\ Universidade Federal de Pernambuco \\ hnwaechter@terra.com.br
}

Resumo: A informação visual sequencial sem palavras geralmente exige maior desempenho do usuário. Experiência e repertório são necessários para uma melhor interpretação da mensagem. Mediante este questionamento, este trabalho pretende compreender a influência da narração na compreensão da mensagem por meio de ações sequenciadas de emojis (ícones digitais da comunicação eletrônica) da propaganda "Mudança" do banco Itaú. Realizou-se um comparativo retórico da compreensão informacional, com e sem influência da narração (jingle/áudio), entre usuários especialistas (designers) e não especialistas (não-designers). Para isso foram abordados estudos dos campos do Design da Informação, Quadrinhos e Retórica Visual. Constatou-se que o nível verbal, por meio da narração do jingle, pode apresentar diferentes tipos de influências na interpretação da informação a depender da sua construção retórica.

Palavras-chave: narração, ação, retórica visual, emoji, usuário.
Abstract: The sequential visual information without words usually requires higher user performance. Experience and repertoire are necessary for a better interpretation of the message. Through this questioning, this study aims to understand the narration influence in understanding the message through sequenced emojis actions (digital icons of electronic communication) at the advertising "Mudança" by Itaú bank. We conducted a rhetorical comparative of the information understanding, with and 
without narration influence (jingle / audio), from specialists (designers) and non-specialists (non-designers). It were approached sudies from the fields of Information Design, Comics and Visual Rhetoric. It was found that the verbal level of narration of the jingle can present different types of influences in the interpretation of information. It depends on its rhetorical construction.

Keywords: narration, action, visual rhetoric, emoji, user.

\section{INTRODUÇÃO}

Em março de 2015 o banco Itaú lançou uma nova campanha publicitária, baseada em elementos visuais já massivamente utilizados no ambiente da comunicação digital: os Emojis. De origem japonesa, "emoji" significa "pictograma", ou "imagem" (e) em "caractere" (moji) (GROVES, 2014; LUCAS, 2016). Esses pequenos ícones digitais expressam ideias, emoções e gestos na comunicação eletrônica. Cada emoji é indicado por um código, controlado pela Unicode Consortium, e cada plataforma operacional desenvolve seu design, ou seja, sua própria representação (DRAFT..., 2015). A partir dos emojis representados pela Apple (comumente conhecidos como os emojis do Whatsapp) e da apropriação e redesign de alguns deles, o banco Itaú desenvolveu narrativas a partir da utilização sequencial desses elementos acompanhados por jingles. A combinação desses elementos representou ações através de filmes curtos, numa campanha publicitária de temáticas variadas relacionadas ao "mundo digital".

Eisner (1999) define que a arte sequencial é possível sem palavras, mas exige maior desempenho cognitivo do leitor ou espectador. Considerando a narração do jingle do objeto de pesquisa como as "palavras" ou como denomina Malamed (2009), o canal verbal da mensagem, usuários foram questionados sobre o que justificaria suas definições sobre as ações. A retórica visual foi utilizada como instrumento de análise dessas características, e comprovação de dados sobre a fundamentação. Para Bonsiepe (2011, p. 146) "usam-se técnicas retóricas implicitamente ou explicitamente na comunicação para aumentar a eficácia comunicativa".

Portanto, o objetivo principal dessa pesquisa foi compreender e comprovar a influência da narração através da interpretação dos usuários sobre as ações dos emojis especificamente no do vídeo "Mudança", um dos filmes da campanha do Itaú. Para isso foram abordados estudos dos campos do Design da Informação, Quadrinhos e Retórica Visual. Foi realizado um comparativo retórico da compreensão informacional, com e sem influência da narração, que neste experimento foi considerada através do jingle (áudio), entre usuários especialistas (designers) e não especialistas (nãodesigners).

\section{CONCEITUAÇÃO}

\subsection{Ação e Narração}

Para este artigo foi considerado que o jingle publicitário do objeto analisado, apesar de possuir outras características e funções como a melodia chave do banco Itaú, correspondeu à definição de narração no que se refere à enunciação verbal, nem 
sempre descritiva/literal das ações dos emojis. Narração é definida por Reis e Lopes (1988, p. 58-60) como um "processo de enunciação narrativa", não necessariamente descritiva, e "um ato e processo de discurso narrativo".

Aragão e Wanderley (2007) definem "ação" como um conjunto de movimentos e suas características dentro de uma sequência. No âmbito dos quadrinhos, o conjunto dessas ações compõem um enredo (McCLOUD, 2008, p. 12-13). Uma ação pode ser compreendida por uma personagem dançando flamenco por exemplo, em que realiza diversos movimentos em quadros diferentes e justapostos.

McCloud (2008, p. 15) categoriza 6 tipos de transição quadro a quadro nos quadrinhos, que influenciam o enredo e a percepção do leitor/usuário: Momento a momento - uma única ação retratada em uma série de momentos; Ação a ação - um mesmo sujeito em uma série de ações; Sujeito a sujeito - uma série de sujeitos alternantes dentro de uma única cena; Cena a cena - ações diferenciadas de cenas diferentes são representadas entre quadros com distâncias significativas de tempo e/ou espaço; Aspecto a aspecto - ações diferenciadas de aspectos diferentes de uma mesma cena ou ideia; Non sequitur - ações diferenciadas são representadas entre quadros em que não há uma sequência lógica.

As ações e narrações da narrativa do vídeo aqui definidas foram elementos de suma importância na presente pesquisa, representadas por variáveis desenvolvidas na metodologia adiante.

\subsection{Linguagem Visual: integração verbal e visual}

A linguagem visual não privilegia apenas a imagem, já que esse estudo iniciado a partir dos anos 80 integra o texto e a imagem numa unidade comunicacional síntese necessária para uma maior rapidez na compreensão da informação (HORN, 1998). Considerando o objeto de estudo dessa pesquisa uma propaganda que possui diferentes níveis comunicativos integrados (emojis como elementos visuais e jingle como elemento de narração verbal), foi possível traçar semelhanças com as teorias da linguagem visual que fundamentaram e definiram as variáveis e o modelo de análise retórica, como será explicitado na metodologia.

Eisner (1999, p. 24), no âmbito da arte sequencial, explica que símbolos e sínteses são melhores compreendidos quando há uma amplitude verbal e visual (diálogo, objetos, acessórios, elementos arquitetônicos e de natureza, vestuário, expressões faciais, entre outros) que como combinados podem gerar ideias diferentes. Define que a arte sequencial é possível sem palavras, mas exige mais desempenho cognitivo do leitor ou espectador. A experiência comum e o repertório de observação são necessários para uma melhor interpretação da mensagem.

Malamed (2009, p. 36) define que a informação verbal e visual são processadas através de canais separados, numa dupla codificação. Apesar dos sistemas de cada canal serem independentes, eles se comunicam e interagem entre si. Ela justifica que uma informação é melhor memorizada devido a esse aspecto de percepção cognitiva, como por exemplo um gráfico com legendas, e uma animação com áudio verbal.

\subsection{Retórica Visual}

Em meio a uma enorme quantidade de dados, tanto verbais quanto visuais, a retórica pode adquirir uma função de natureza cognitiva, em que instrumentos retóricos são utilizados para facilitar a compreensão de informações. O tema tem sido 
estudado sob os mais variados aspectos desde a Antiguidade, do ponto de vista da linguística, mas a abordagem da imagem como linguagem com sua própria retórica iniciou-se no século XX (ALMEIDA \& NOJIMA, 2010).

Bonsiepe (2011, p. 117) refere-se aos atributos estilísticos de uma composição textual, que podem ser adaptados para uma análise da imagem. Eles são nomeados pelo autor como patterns retóricos, ou "a arte de dizer algo em nova forma". A partir da terminologia semiótica, o autor estabelece dois tipos de patterns:

- Patterns sintáticos: operação com a forma do sinal;

- Patterns semânticos: operação com o significado.

Horn (1998, p. 54) define que a linguagem visual promove alternativas verbais e visuais para problemas retóricos e, portanto, investigações na retórica da linguagem visual são mais fáceis quando a sintaxe e a semântica são reconhecidos. Assim, os níveis sintáticos e semânticos da propaganda do Itaú, e sua relação com os patterns visual-verbais definidos por Bonsiepe (2011, p. 118), serão analisados adiante.

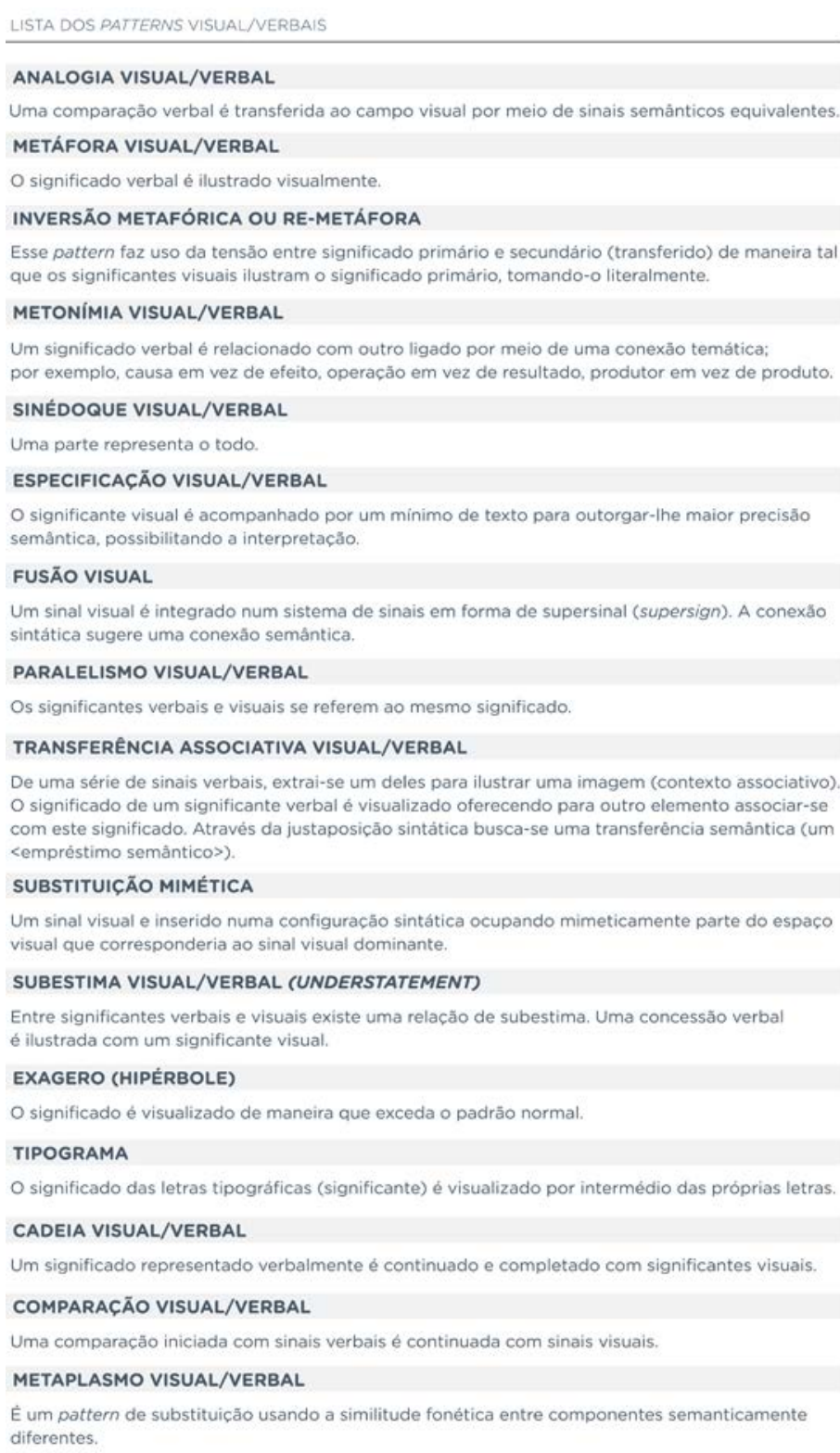

Figura 1 - Lista dos patterns visual-verbais de Bonsiepe (2011). Fonte: Bonsiepe (2011, p. 118). 


\section{METODOLOGIA E DESENVOLVIMENTO}

A metodologia desta pesquisa foi dividida em 6 fases. Na primeira, seleção da amostragem, o objeto de pesquisa foi definido com base na classificação proposta por McCloud (2008, p. 15), dividindo o vídeo em 6 recortes. Na segunda fase, levantamento de dados, foi realizada uma pesquisa com os vídeos, através de formulários online, em que foi-se questionado ao usuário qual ação era percebida e quais características o levaram a essa conclusão. Na terceira, definição das ações, os dados relacionados à primeira pergunta dos questionários foram utilizados para definir qual a ação foi mais compreendida em cada vídeo. Já na quarta, seleção das características, as respostas dos usuários relacionadas ao motivo do reconhecimento da ação foram analisadas e divididas em aspectos de forma (sintáticos) e ideia (semânticos). Na fase cinco, análise retórica, as ações definidas na terceira fase e as características observadas pelos usuários na fase seguinte, foram utilizadas para preencher a ferramenta de análise retórica utilizada neste artigo, desenvolvida a partir dos estudos de Bonsiepe (2011, p. 118) e Horn (1998, p. 99-100). Por fim, na sexta e última fase, discussão dos resultados, os dados foram atentamente analisados a fim de responder as perguntas da pesquisa.

\subsection{Seleção da Amostragem}

Partindo da definição de ação de Aragão e Wanderley (2007, p. 3), é possível identificar 13 ações diferentes na propaganda analisada. Destas, 6 foram escolhidas como recorte, baseadas na classificação proposta por McCloud (2008, p. 15).

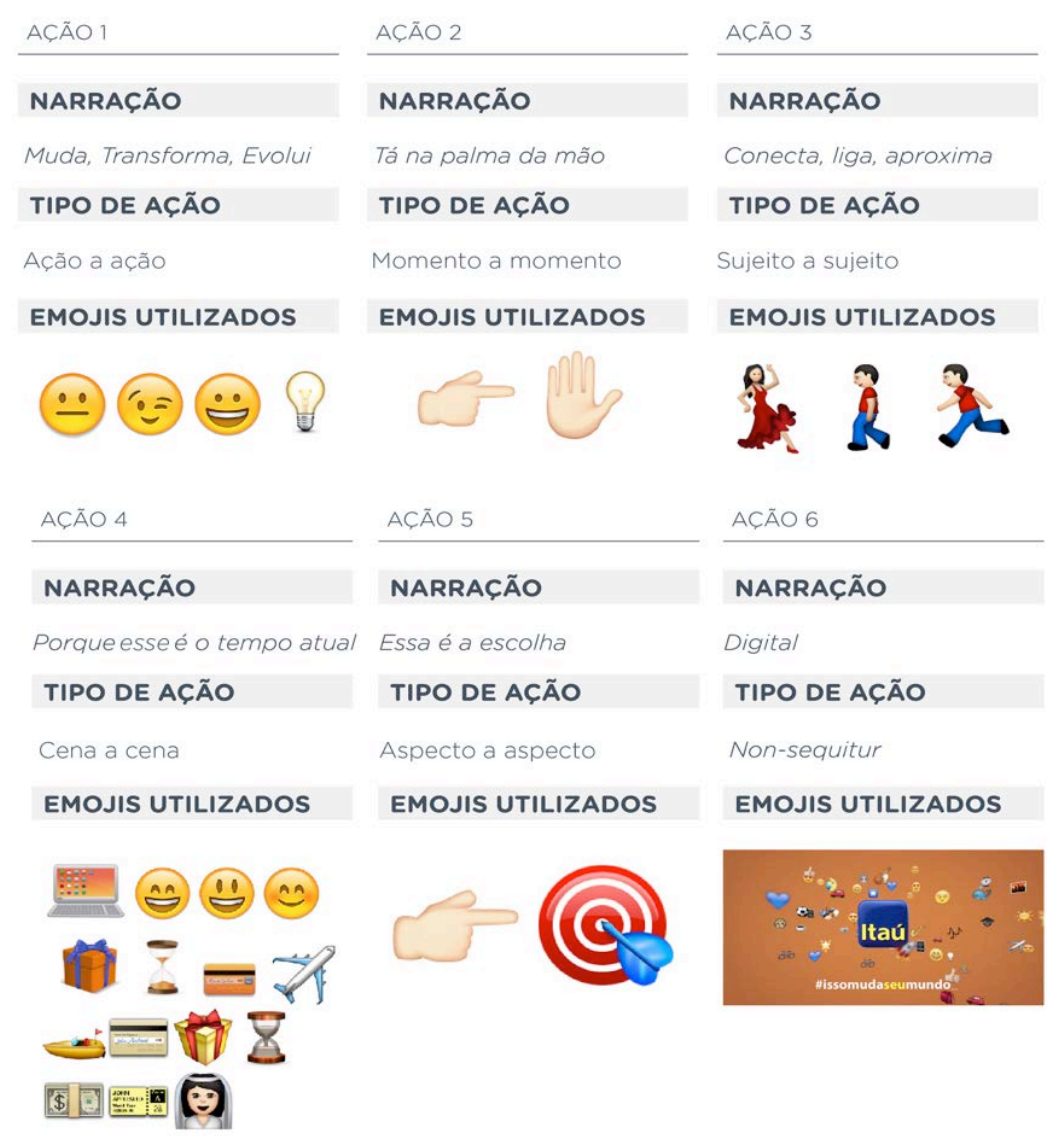

Figura 2 - Recorte a ser analisado das ações da propaganda Mudança. Fonte: Elaborado pelos autores, com base na pesquisa realizada. Imagens capturadas da propaganda online (ITAÚ, 2015). 


\subsection{Levantamento de Dados}

Selecionadas as ações, foram construídos dois formulários em plataforma online. No primeiro formulário os vídeos foram veiculados sem áudio, diferente do segundo que acompanhou o jingle original da propaganda, recortado de acordo com a ação escolhida. Em ambos, os 6 vídeos (ações) foram expostos e acompanhados de duas perguntas cada: a primeira "Qual ação você percebeu no vídeo?" e a segunda "Quais características te levaram a essa conclusão?", seguidas de um exemplo respondido para orientar o usuário no preenchimento. Dados como gênero, idade e profissão também foram solicitados, mas apenas a profissão foi uma variável relevante. Por fim, foi questionado se o usuário já "tinha visto esta campanha publicitária antes", para também medir a influência dessa variável no resultado final.

O formulário foi distribuído em redes sociais e grupos de e-mail visando o maior número de respostas durante o período de uma semana. Foram definidos como Grupo 1 os usuários que responderam ao primeiro formulário (sem áudio), e Grupo 2 os referentes ao segundo (com áudio). No primeiro, 58 pessoas responderam a pesquisa, enquanto que no segundo 32 responderam. Com o objetivo de igualar o dados levantados, foi utilizada a variável profissão como definidora dos dois grupos.

Logo, cada grupo foi composto de $\mathbf{1 0}$ especialistas (designers) e de $\mathbf{1 0}$ não especialistas (não-designers), totalizando $\mathbf{4 0}$ usuários. A variável designer e nãodesigner foi escolhida partindo do pressuposto de que o profissional especialista possui maior intimidade com a temática em questão, o que poderia trazer respostas interessantes para a análise dos dados e seus resultados, além de possibilitar novas observações à pesquisa. O critério de seleção dos 20 usuários de cada grupo foi a ordem cronológica das respostas, ou seja, os primeiros 10 designers e 10 nãodesigners de cada grupo.

\subsection{Definição das Ações}

Definidos os grupos, foi iniciada a análise das respostas. As respostas da primeira pergunta ("Qual ação você percebeu no vídeo?") foram utilizadas para definir as ações em ambos os grupos.

\section{GRUPO 1 SEM ÁUDIO}

\section{AÇÃo 1 Qual ação você percebeu no vídeo?}

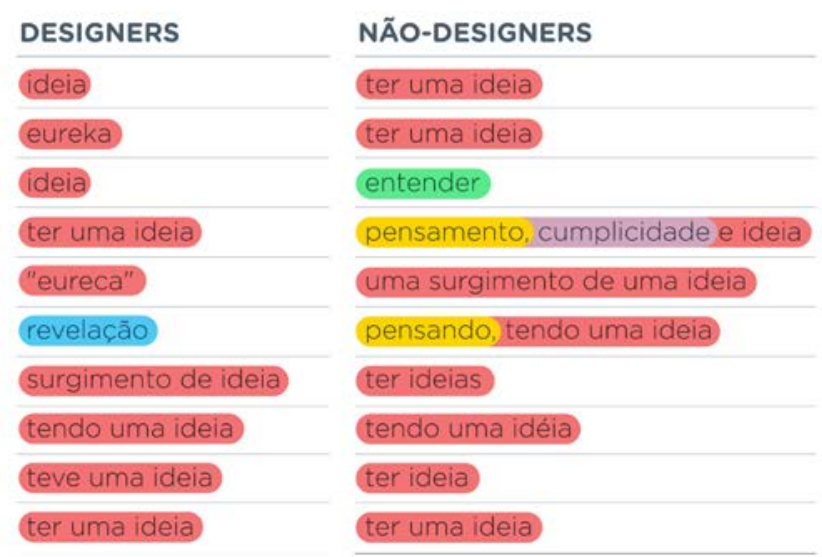

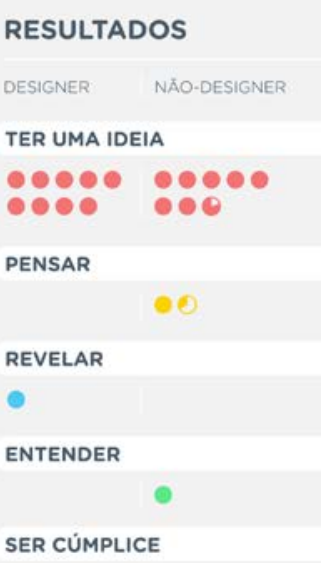

SER CÚMPLICE

Figura 3 - Modelo de análise das respostas para definição das ações (Ação 1/Grupo 1/Ter uma ideia). Fonte: Elaborado pelos autores, com base na pesquisa realizada. 
As definições semelhantes foram agrupadas por cor e as mais mencionadas definiram as ações dos grupos. 0 procedimento foi aplicado às 6 ações de ambos os grupos. Além disso, foram levantadas porcentagens referentes à predominância na definição da ação por designers e não-designers, e se estes já conheciam ou não a propaganda (examinados na Discussão dos Resultados).

Observou-se que quase todas as ações se mantiveram entre os dois grupos (Ter uma ideia, Usar a Internet, Acertar e Englobar), com exceção de dois casos, Ação 2 (Parar - Grupo 1/Sem áudio; Apontar - Grupo 2/Com áudio) e Ação 3 (Dançar - Grupo 1/Sem áudio; Aproximar - Grupo 2/Com áudio), que tiveram definições diferentes.

\subsection{Seleção das Características}

Após a definição das ações, foi iniciada a análise das respostas referentes à segunda pergunta ("Quais características te levaram a essa conclusão?").

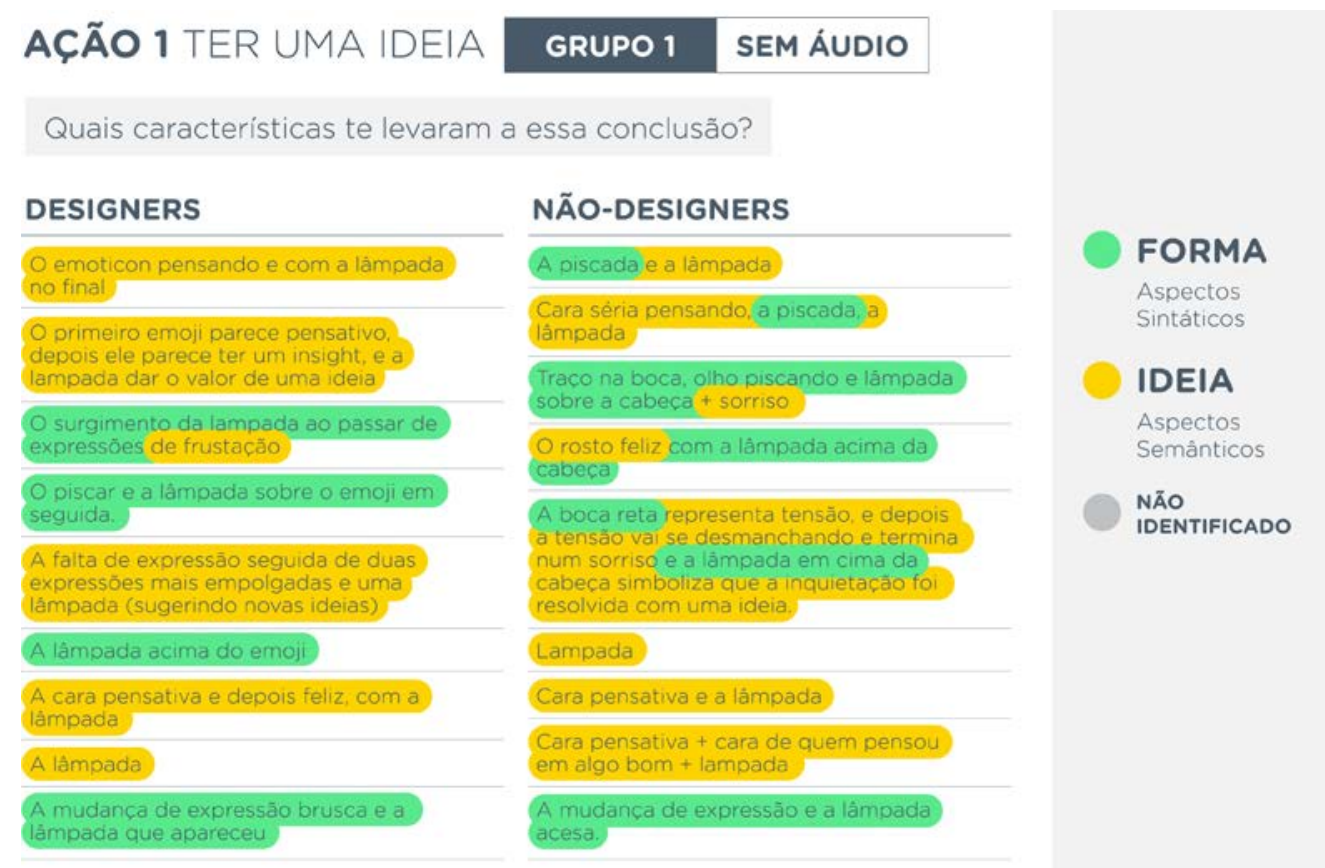

Figura 4 - Modelo de análise das características de Forma e Ideia (Ação 1/Grupo 1). Fonte: Elaborado pelos autores, com base na pesquisa realizada.

O objetivo foi perceber quais elementos influenciaram os usuários a cada definição, e utilizá-los como informações para preenchimento da ferramenta de análise retórica utilizada na pesquisa. A partir das definições dos autores sobre a sintaxe e a semântica na análise retórica, as características relatadas pelos usuários foram divididas em configuração de forma (sintático) e de ideia (semântico). 0 procedimento foi aplicado às 6 ações de ambos os grupos.

\subsection{Análise Retórica}

Após o levantamento das características percebidas pelos usuários, procedeuse a análise retórica. O modelo utilizado nesta pesquisa foi baseado nos autores Horn (1998, p. 99-100) e Bonsiepe (2011, p. 117-118). Horn (1998, p. 99-100) propõe uma tabela da semântica da integração entre elementos verbais e visuais, com o objetivo de melhor visualizar as diferentes configurações destes elementos na linguagem visual. $\mathrm{Na}$ mesma tabela, é identificada a presença de uma figura retórica, baseada na retórica clássica, relacionada a ideia do objeto em análise. 
IDEIA

Apresentar um objeto

inanimado como uma

pessoa. (Em retórica

clássica, prosopopeia)
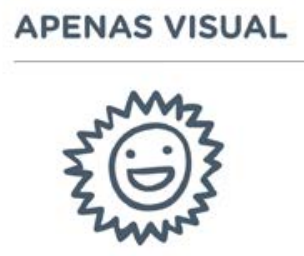

APENAS VERBAL

Aquela manhã, o sol

brilhou sobre nós, como

uma grande face

amigável rodeada de

linguas de fogo.
LINGUAGEM VISUAL

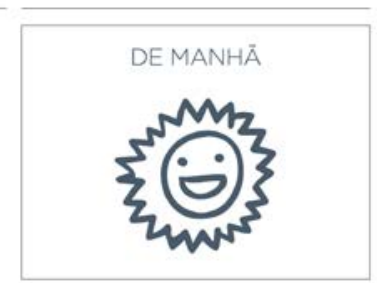

Figura 5 - Tabela da semântica da integração de Horn.

Fonte: Adaptado de Horn (1998, p. 99-100).

Para esta pesquisa foi adicionada a coluna FORMA à tabela, baseada na divisão proposta por Bonsiepe (2011, p. 117), onde os elementos podem ser relacionados à forma e à ideia.

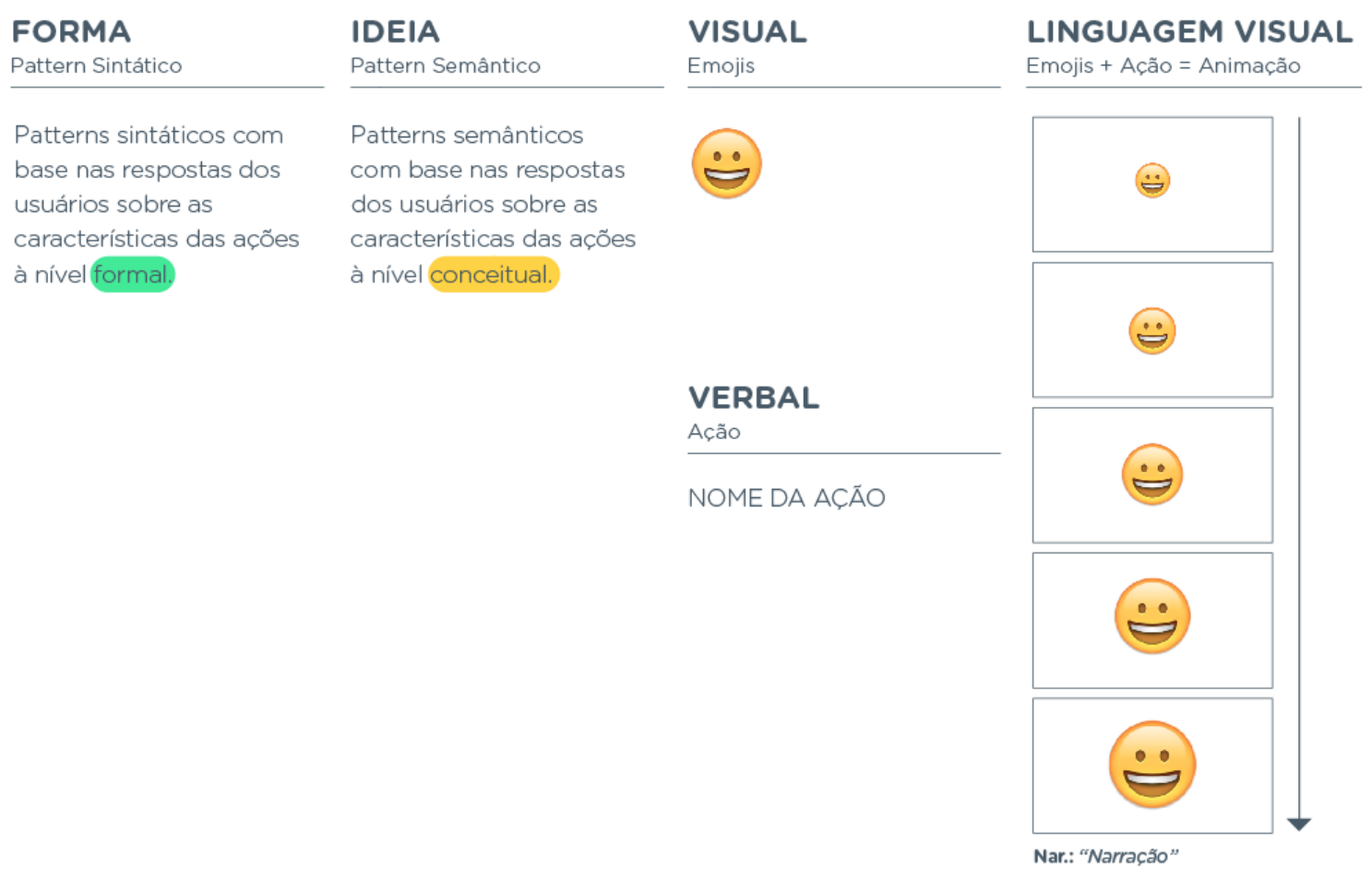

Figura 6 - Modelo da tabela de análise retórica utilizada na pesquisa.

Fonte: Elaborado pelos autores, com base na pesquisa realizada.

No modelo construído, as colunas forma e ideia foram preenchidas a partir das percepções dos usuários e resultaram na identificação dos patterns retóricos. Os emojis utilizados na ação constituíram a coluna visual, e as ações percebidas pelos usuários a verbal. Os frames dos vídeos foram posicionados em linguagem visual, onde o Grupo 1 era constituído por Emojis + Ação = Animação e o Grupo 2 por Emojis + Ação = Ação + Narração (áudio).

Os significantes verbais propostos por Bonsiepe (2011) foram definidos através das falas dos usuários no Grupo 1, e no Grupo 2 por meio das falas mais a influência das narrações (áudio) dos vídeos. Os emojis assumiram o papel dos significantes visuais. A análise retórica foi realizada em todas as 12 ações ( 6 de cada grupo), e todos os dados até então levantados foram determinantes para o preenchimento da tabela de análise. A voz do usuário foi representada com texto entre aspas. 


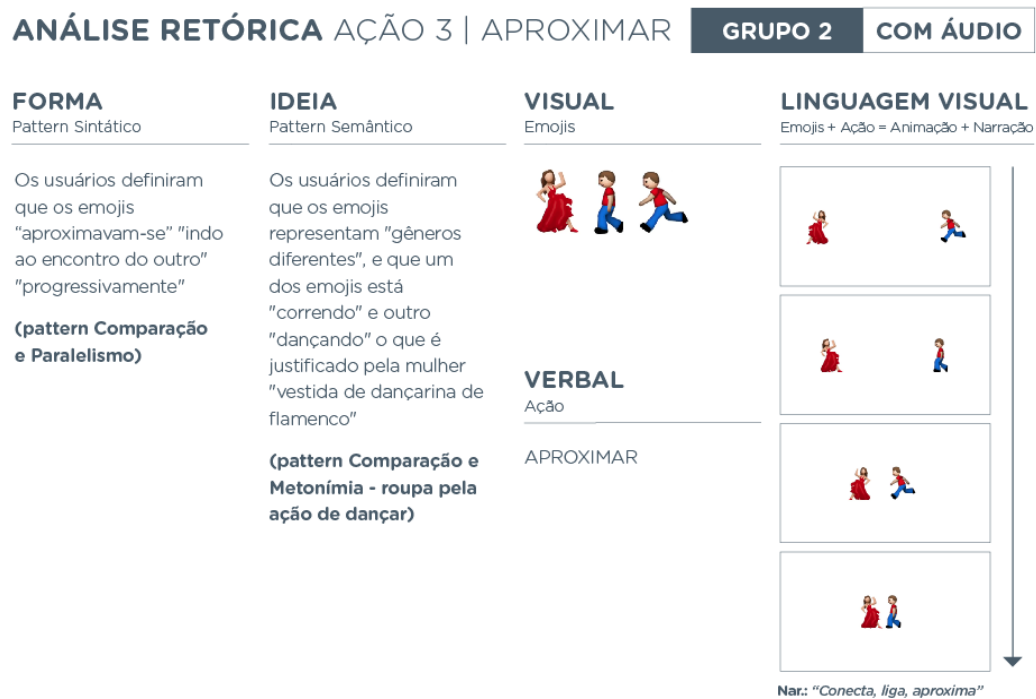

Figura 7 - Exemplo de análise retórica (Ação 3/Grupo 2/Aproximar). Fonte: Elaborado pelos autores, com base na pesquisa realizada.

Após a análise completa, foram encontrados 10 tipos de patterns diferentes, distribuídos em 41 ocorrências: Analogia 5\%, Comparação 22\%, Exagero 5\%, Cadeia, 22\%, Metáfora 17\%, Metonímia 7\%, Transferência Associativa 5\%, Paralelismo 9,5\%, Sinédoque 2,5\%, Fusão Visual 5\%). Notou-se predominância em ambos os grupos dos patterns Comparação, Cadeia e Metáfora. O aumento da ocorrência do pattern Paralelismo foi o mais acentuado na transição do Grupo 1 para o Grupo 2.

\section{DISCUSSÃO DOS DADOS}

Com o cruzamento entre as variáveis definição da ação, designers e nãodesigners, com áudio e sem áudio e conhecimento ou não da propaganda, foi possível observar que no Grupo 1 (sem áudio/sem narração) os que mais influenciaram na definição das ações foram os não-designers (55,35\%), dos quais $66 \%$ não conheciam a propaganda. Já no Grupo 2 (com áudio/com narração) os que mais influenciaram na definição das ações foram os designers $(54,65 \%)$, dos quais $53 \%$ conheciam a propaganda.

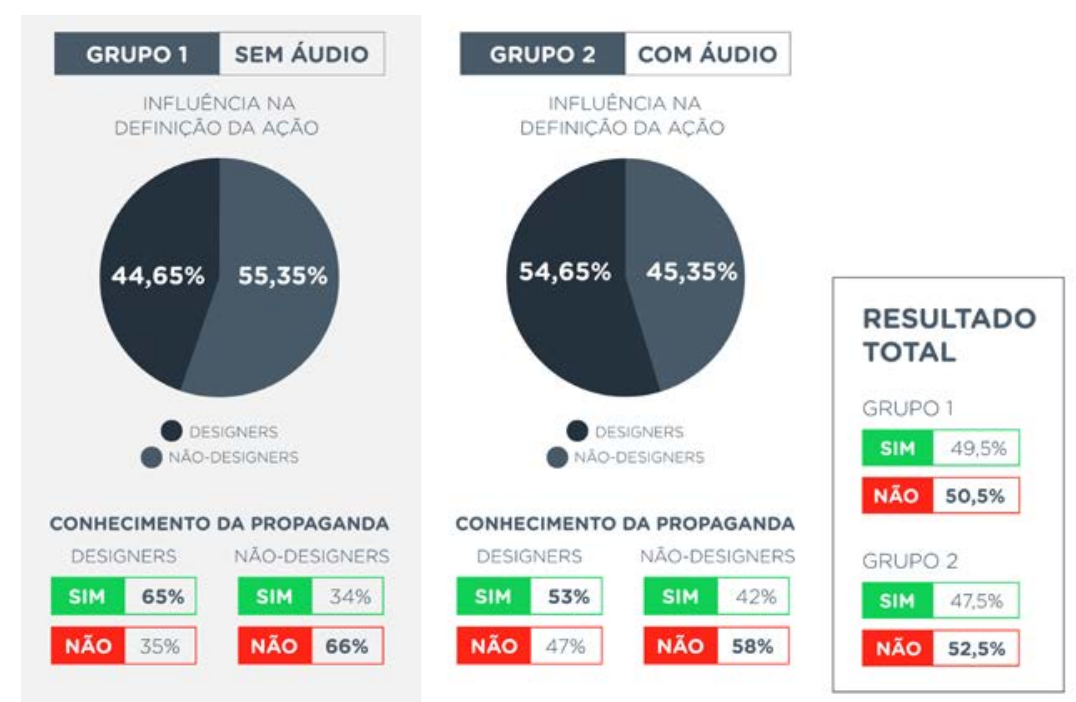

Figura 8 - Tabela de cruzamento de dados entre variáveis da pesquisa. Fonte: Elaborado pelos autores, com base na pesquisa realizada. 
A variável conhecimento da propaganda não influenciou nas definições das ações, uma vez que no Grupo 1 os não-designers tiveram maior participação na escolha da ação ao mesmo tempo que sua maioria não tinha conhecimento da propaganda. Além disso, no resultado total, independentemente da profissão, ambos grupos não conheciam a propaganda (Grupo 1 [50,5\%] e Grupo 2 [52,5\%]).

Com o cruzamento entre as variáveis designers e não-designers, com áudio e sem áudio e forma e ideia, foi possível observar que no Grupo 1 houve predominância de compreensão da ideia pelos usuários (designers [49,5\%] e não-designers [57,5\%]), ou seja, de aspectos conceituais das ações na ausência de narração. Enquanto no Grupo 2, predominou a forma (designers [66\%] e não-designers [57\%]), ou seja, aspectos formais e configuracionais das ações na presença da narração.
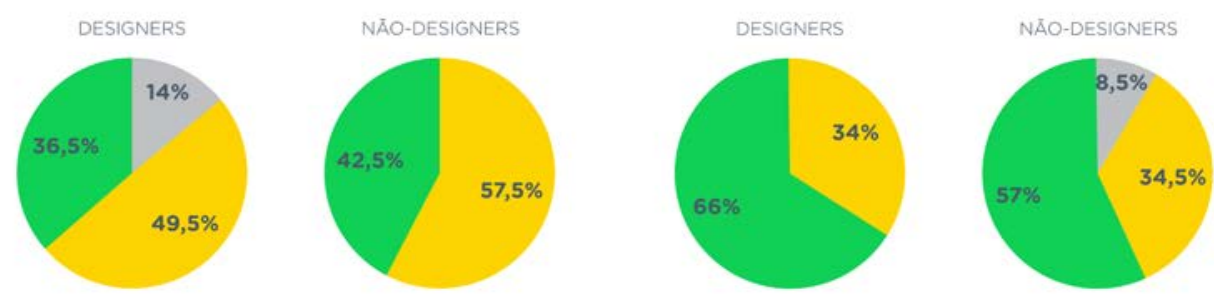

- forma ideia não identificado

- forma ideia enáoidentificado

Figura 9 - Comparativo entre a compreensão de Forma e de Ideia pelo Grupo 1 e Grupo 2. Fonte: Elaborado pelos autores, com base na pesquisa realizada.

Partindo para os resultados obtidos através da análise retórica, foi construído um quadro comparativo utilizando as variáveis forma e ideia, com áudio e sem áudio e os patterns retóricos identificados no processo.

\section{COMPARATIVO DE RESULTADOS PATTERNS RETÓRICOS}

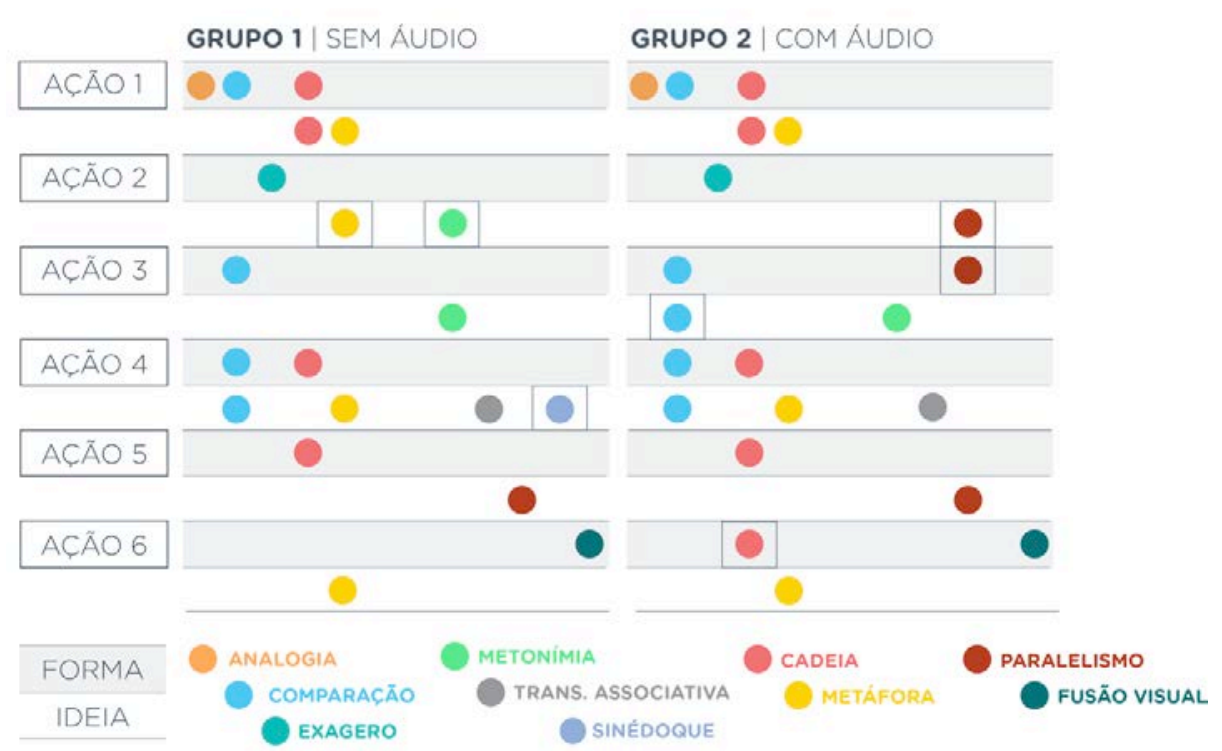

Figura 10 - Comparativo da ocorrência dos patterns retóricos no Grupo 1 e Grupo 2. Fonte: Elaborado pelos autores, com base na pesquisa realizada. 
Na Ação 1 (Ter uma ideia) e na Ação 5 (Acertar) os patterns foram iguais em ambos os grupos: a convenção da Metáfora da lâmpada como "ter uma ideia" da Ação 1 e a perceptível sequencialidade da ação representada pelo pattern Cadeia da Ação 5 facilitaram a congruência dos resultados das ações. Na Ação 2 (Parar e Apontar) houve uma mudança de interpretação retórica no nível semântico: no Grupo 1, os patterns Metáfora e Metonímia tiveram relação direta com aspectos relacionados à convenção do símbolo "parar" (exibição da palma da mão), enquanto que no Grupo 2 (com áudio) foram substituídos pelo pattern Paralelismo, que faz uma relação entre o significado da interpretação do usuário (influenciado pela narração) e os emojis que correspondem à narração, modificando a compreensão geral da ação. Na Ação 3 (Dançar e Aproximar) houve uma mudança de interpretação retórica devido ao adicional de dois patterns a mais no Grupo 2: Comparação resultante da interpretação do usuário (influenciado pela narração) e os emojis de "gêneros diferentes" "correndo" e "dançando"; e o Paralelismo da relação direta dos emojis com a narração à nível formal; modificando a compreensão geral da ação. Na Ação 4 (Usar a internet) houve um adicional na interpretação retórica no nível semântico: no Grupo 1 o pattern Sinédoque foi utilizado como uma adição interpretativa do usuário, listando significados a cada emoji disposto ao redor do computador ao centro da composição, porém seu uso não mudou a compreensão geral da mensagem em ambos os grupos. Na Ação 6 houve um adicional na interpretação retórica no nível sintático: no Grupo 2, a descrição detalhada da sequência da ação "Englobar" entre a marca do Itaú e os emojis resultou na ocorrência do pattern Cadeia, porém seu uso não mudou a compreensão geral da ação em ambos os grupos.

\section{CONSIDERAÇÕES FINAIS}

A partir dos dados coletados, analisados, e discutidos, foram identificadas respostas ao problema de pesquisa, além de novas informações.

Foi observado que quando houve narração (áudio) e esta teve relação direta, seja ela sintática ou semântica, com a ação representada visualmente (AÇÃO 2: "Ta na palma da mão" / Uma mão apontando para a palma da mão; AÇÃO 3: "Conecta, liga, aproxima" / Homem e mulher se aproximando), a ação definida foi diferente entre os dois grupos (com áudio e sem áudio), sofrendo influência da narração. Os significantes visuais destas ações possuíam diferentes significados dependendo do contexto e a narração (jingle) foi primordial para a definição das mesmas. Isso justifica a incongruência das definições da Ação 2 e Ação 3 entre o Grupo 1 (sem áudio) e Grupo 2 (com áudio).

Foi observado também que quando houve narração (áudio) e esta não teve relação direta com a ação representada visualmente (AÇÃO 1: "Muda, transforma, evolui" / Uma lâmpada surgindo acima da cabeça; AÇÃO 4: "Porque isso é o tempo atual" / Emojis rodeando computador; AÇÃO 5: "Essa é a escolha" / Dardo atingindo alvo; AÇÃO 6: "Digital" / Emojis rodeando marca do Itaú), a ação definida manteve-se igual nos dois grupos (com áudio e sem áudio), não sofrendo influência da narração. Os significantes visuais destas ações faziam parte do repertório simbólico dos usuários (em sua maioria convenções como a lâmpada e o dardo) e a narração teve função complementar, não definidora. Isso contribui com a definição de Eisner (1999) sobre a influência da linguagem verbal: se não há, exige-se maior desempenho do usuário. 
Notou-se que os não-designers obtiveram maior compreensão quando a imagem foi apresentada sem auxílio verbal (narração), diferentemente dos designers. As convenções/ideias foram melhor compreendidas pela maioria dos usuários na ausência de uma narração. Já a compreensão dos aspectos formais foram maiores quando houve narração, o que contribui com a definição de Malamed (2009) de que as informações são mais facilmente memorizadas (processo que exige a formalização do conteúdo mentalmente) quando há integração verbal e visual. A presença da narração também foi determinante para o surgimento do pattern (BONSIEPE, 2011) Paralelismo no segundo grupo (com áudio), este que se refere à semelhança de significado entre a interpretação do usuário (influenciado pela narração) e os emojis.

Logo, foi comprovada nesta pesquisa a importância da integração visual/verbal na compreensão de uma mensagem. Porém, constatou-se que o nível verbal, por meio da narração do jingle, pode apresentar diferentes tipos de influências na interpretação da informação a depender da sua construção retórica.

\section{REFERÊNCIAS}

ALMEIDA JUNIOR, Licínio de; NOJIMA, Vera Lúcia. Retórica do design gráfico: da prática à teoria. Coleção Pensando o Design, Marcos Braga, coordenador. São Paulo: Blucher, 2010.

ARAGÃO, Isabella Ribeiro; WANDERLEY, Renata Garcia. Representação de ação: uma evolução das mídias estáticas para dinâmicas. In: Anais do XXX Congresso Brasileiro de Ciências da Comunicação, Intercom, 2007. São Paulo: Intercom, 2007. Disponível em: $\quad$ http://www.intercom.org.br/papers/nacionais/2007/resumos/R1594-1.pdf>. Acesso em 20 set. 2015

BONSIEPE, Gui. Design, Cultura e Sociedade. São Paulo: Blucher, 2011.

EISNER, Will. Quadrinhos e arte sequencial. São Paulo: Martins Fontes, 1999.

HORN, Robert E. Visual Language: Global Communication for the 21st Century. Bainbridge Island: MacroVU Press, 1998.

DRAFT Emoji Data (full). List of emoji characters, with images maintened by Unicode, 2015. Disponível em: <http://www.unicode.org/Public/emoji/1.0/full-emoji-list.html> . Acesso em 20 abr. 2015.

GROVES, Emily. Not just a pretty face. An archaeology and critical analysis of the emoji. M.A Dissertation - Royal College of Art, Information Experience Design, Londres, 2014.

ITAÚ. Mudança. Disponível em: <https://www.youtube.com/watch?v=0lUU_7gWXx8>. Acesso em: 31 ago. 2015.

LUCAS, Gavin. The Story of Emoji. Munique, Londres, Nova York: Prestel, 2016.

MALAMED, Connie. Visual Language for Designers. Beverly: Rockport Publishers, 2009.

McCLOUD, Scott. Desenhando quadrinhos. São Paulo: M. Books, 2008.

REIS, Carlos; LOPES, Ana Cristina M. Dicionário de Teoria da Narrativa. São Paulo: Editora Ática, 1988. 